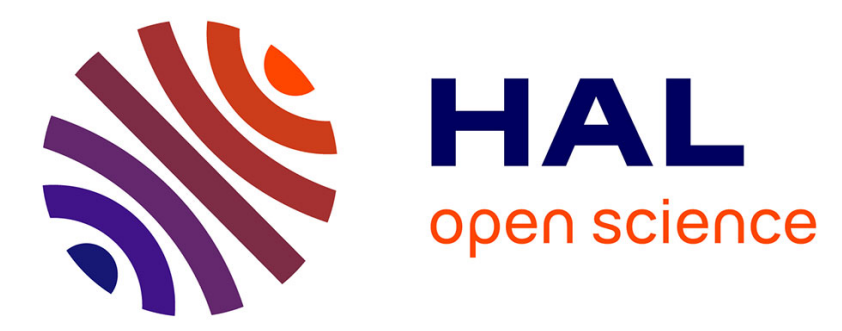

\title{
Laser-assisted atom probe tomography of semiconductors: The impact of the focused-ion beam specimen preparation
}

J. Bogdanowicz, A. Kumar, C. Fleischmann, M. Gilbert, J. Houard, A. Vella, W. Vandervorst

\section{To cite this version:}

J. Bogdanowicz, A. Kumar, C. Fleischmann, M. Gilbert, J. Houard, et al.. Laser-assisted atom probe tomography of semiconductors: The impact of the focused-ion beam specimen preparation. Ultramicroscopy, 2018, 188, pp.19-23. 10.1016/j.ultramic.2018.03.001 . hal-02061734

\section{HAL Id: hal-02061734 https://hal.science/hal-02061734}

Submitted on $20 \mathrm{Jul} 2020$

HAL is a multi-disciplinary open access archive for the deposit and dissemination of scientific research documents, whether they are published or not. The documents may come from teaching and research institutions in France or abroad, or from public or private research centers.
L'archive ouverte pluridisciplinaire HAL, est destinée au dépôt et à la diffusion de documents scientifiques de niveau recherche, publiés ou non, émanant des établissements d'enseignement et de recherche français ou étrangers, des laboratoires publics ou privés. 


\title{
Laser-assisted atom probe tomography of semiconductors: The impact of the focused-ion beam specimen preparation
}

\author{
J. Bogdanowicz ${ }^{\text {a,*, A. Kumar }}{ }^{\mathrm{a}, \mathrm{b}}$, C. Fleischmann ${ }^{\mathrm{a}}$, M. Gilbert ${ }^{\mathrm{c}}, \mathrm{J}$. Houard ${ }^{\mathrm{c}}$, A. Vella ${ }^{\mathrm{c}}$, \\ W. Vandervorsta, ${ }^{\mathrm{a}} \mathrm{b}$ \\ a IMEC, Kapeldreef 75, B-3000 Leuven, Belgium \\ ${ }^{\mathrm{b}}$ Instituut voor Kern- en Stralingsfysika, KU Leuven, Celestijnenlaan 200D, B-3001 Leuven, Belgium

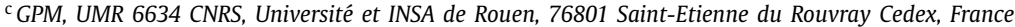

\begin{abstract}
A B S T R A C T
This paper demonstrates the increased light absorption efficiency of semiconducting atom probe tips resulting from focused-ion-beam (FIB) preparation. We use transmission electron microscopy to show that semiconducting tips prepared with FIB are surrounded with an amorphized shell. Photomodulated optical reflectance measurements then provide evidence that FIB-induced damage leads to an increase in both sub- and supra-bandgap light absorption efficiency. Using laser-assisted atom probe tomography (La-APT) measurements, we finally show that, for a nanoscale tip geometry, the laser-induced heating of a tip during La-APT is enhanced by the FIB preparation. We conclude that, upon supra-bandgap illumination, the presence of a FIB-amorphized surface dramatically increases the light-induced heat generation inside semiconducting tips during La-APT. Furthermore, we also deduce that, in the intriguing case of sub-bandgap illumination, the amorphization plays a crucial role in the unexpected light absorption.
\end{abstract}

\section{Introduction}

Laser-assisted atom probe tomography (La-APT) is a measurement technique based on the atom-by-atom evaporation from a sharp conical tip under the combined effects of a strong standing voltage and a pulsed laser [1,2]. The sharp tip is typically fabricated using a focused ion beam. While the voltage is used to induce a very intense electric field at the tip apex, the laser generates a thermal pulse inside the tip leading the apex atoms to become ionized and subsequently ejected from the tip [3]. Though successful La-APT measurements have been reported on materials and structures ranging from metals to semiconductors and insulators [2-5], the underlying fundamental physics of the technique is still poorly understood. As a matter of fact, the actual mechanism which allows the laser pulse to trigger the evaporation of atoms from the tip apex remains to be understood [3]. An example showing the limited physical insight into the laser-tip interaction is the intriguing observation that materials which are a priori transparent to the laser wavelength applied can still be evaporated. Indeed, La-APT analysis of wide-bandgap semiconductors and insulators has been achieved with sub-bandgap lasers [6-10]. Previous work suggests

\footnotetext{
* Corresponding author.

E-mail addresses: Janusz.Bogdanowicz@imec.be, janusz@imec.be (J. Bogdanow-
}

that this may be explained by a metallic transition the tip undergoes when subjected to the very intense electric fields needed for evaporation [11,12]. However, up to now, all attempts to model these complex interactions assume purely crystalline tips, thus ignoring the role of the damage created through the interaction of the energetic $\mathrm{Ga}^{+}$beam with the tip material during its preparation using a focused ion beam (FIB) [13]. Moreover, the FIB-induced damage can be expected to have a major impact because it is already known that, compared to their crystalline counterparts, FIBamorphized semiconductors exhibit dramatically altered properties $[14,15]$.

In this paper, we demonstrate that the damage induced by FIB contributes significantly to the absorption of both supra- and sub-bandgap laser light. To simultaneously study supra- and subbandgap illumination, both (001) $\mathrm{Si}$ (bandgap $\mathrm{E}_{\mathrm{g}}=1.1 \mathrm{eV}$ [16]) and wurzite (0001) GaN ( $E_{g}=3.5 \mathrm{eV}$ [17]) illuminated with nearinfrared (NIR) to visible light are considered. We start by showing with transmission electron microscopy (TEM) that preparing tips with FIB results in an amorphized shell surrounding the complete tip. Photomodulated optical reflectance (PMOR) measurements [18-20] were then used to demonstrate that FIB-amorphized Si and GaN (resp. $\alpha$-Si and $\alpha$-GaN) exhibit a dramatically higher absorption efficiency compared with their crystalline $\mathrm{Si}$ (c-Si) and crystalline GaN (c-GaN) counterparts. Finally, we confirm the FIBinduced enhancement of the absorption efficiency of Si and GaN 

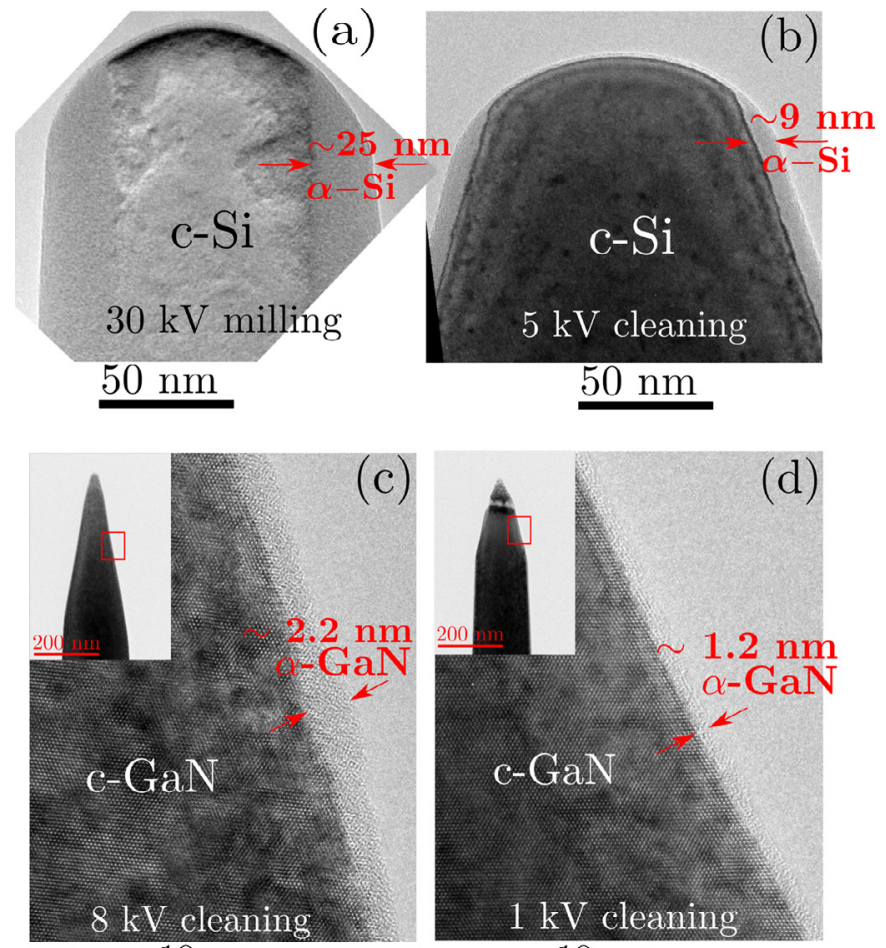

$10 \mathrm{~nm}$

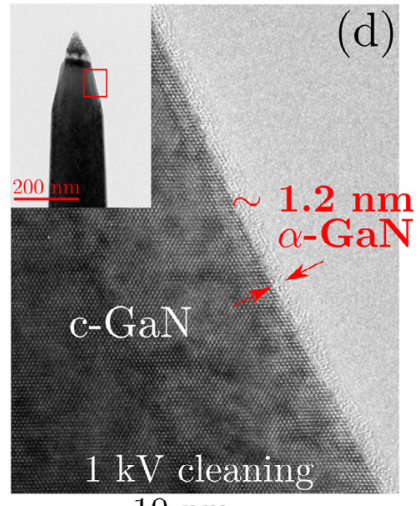

$10 \mathrm{~nm}$

Fig 1. (Top) Transmission electron micrographs of the Si tips (a) milled with a $30 \mathrm{kV}$ $\mathrm{Ga}^{+}$beam and (b) cleaned with a $5 \mathrm{kV} \mathrm{Ga}^{+}$beam showing $\alpha-\mathrm{Si}$ shells of $\sim 25 \mathrm{~nm}$ and $\sim 9 \mathrm{~nm}$ thickness respectively. These 2 micrographs were acquired after La-APT analysis, which explains the absence of an amorphized layer on top of the tip apex. (Bottom) Transmission electron micrographs of the sidewalls of GaN tips milled at $30 \mathrm{kV}$ and cleaned at (c) $8 \mathrm{kV}$ and (d) $1 \mathrm{kV}$ again showing $\alpha$-GaN shells of $\sim 2.2 \mathrm{~nm}$ and $\sim 1.2 \mathrm{~nm}$ thickness respectively. Inset: complete GaN tip shapes before analysis. The red box highlights the region of the magnified sidewall. Fig. (a) was obtained with an FEI Tecnai F30 operating at $300 \mathrm{kV}$, Fig. (b) with Cs-probe-corrected JEOL ARM 200F equipped with a Schottky field emitter and operating at $200 \mathrm{kV}$ and (c) and (d) with an FEI Titan operating at $300 \mathrm{kV}$.

atom probe tips by conducting a laser-assisted atom probe experiment and looking at the impact on the evaporation flux of the final FIB acceleration voltage used for tip preparation. We conclude that the FIB-amorphized shell plays a major role in the physics behind the heat generation during laser-assisted field evaporation of semiconducting APT tips. Hence, the amorphized shell should be included in any attempt to model the interactions involving suprabandgap and sub-bandgap illumination.

\section{Ion beam damage in a semiconducting specimen}

Most atom probe tips made of semiconducting or insulating materials are prepared using the micromachining capabilities of FIB [21]. To shape the sample into the conical tip required for LaAPT analysis, an energetic $30 \mathrm{kV}$ focused $\mathrm{Ga}^{+}$beam is used to remove the unwanted material. However, a side effect involves each incident $\mathrm{Ga}^{+}$ion triggering a collision cascade inside the tip, which damages and eventually amorphizes the tip surface by generating a high density of interstitials. This process has been studied extensively in the field of ion implantation [23] and shown that a minimum dose is required to form a fully amorphized layer. Full amorphization is both energy- and mass-dependent, but typically requires a dose in the range $10^{14}-10^{15} \mathrm{~cm}^{-2}$ [24,25].

The TEM micrograph of Fig. 1(a) shows the resulting $\sim 25-\mathrm{nm}$ thick amorphized shell at the surface of a Si tip milled with a $30 \mathrm{kV}$ $\mathrm{Ga}^{+}$beam. To reduce the extent of the damage, the tip preparation usually includes a "cleaning" step with a lower energy beam. As

\section{Edited by Foxit PDF Editor Copyright (c) by Foxit Corporation, 2003 - 2010 For Evaluation Only.}

can be noted in Fig. 1(b), cleaning with e.g. a $5 \mathrm{kV}$ beam indeed results in a thinner $\sim 9$-nm amorphized shell. A similar decrease in the amorphized shell thickness using a lower acceleration voltage is also observed for GaN tips (Fig 1(c) and (d)), with both cases initially being milled at $30 \mathrm{kV}$ but cleaned using $8 \mathrm{kV}$ and $1 \mathrm{kV}$ respectively. This decreasing thickness is expected because the ion penetration depth and subsequent collision cascade scale with incident ion energy $[22,23]$. However, though the thickness of the damaged layer drops with decreasing ion beam energy, all the tips prepared with FIB will still have some amorphized shell. A simple calculation of the ion dose/pixel in the FIB indicates that, even for low-current $(\sim 10 \mathrm{pA})$ imaging of the tip and a $10 \times 10 \mu \mathrm{m}^{2}$ field of view, the amorphization dose is reached and a stationary amorphized region formed in only a few seconds. The results presented in this paper are therefore equally relevant to tips just imaged with FIB.

In this paper, the FIB preparation was done on FEI Helios 450 using the lift out method [21]. To protect the surface from ion damage, initially a $1 \mu \mathrm{m}$ Pt layer was deposited on the surface. During the final annular milling step the Pt protective cap was completely removed using low $\mathrm{kV}$ cleaning step (1-30 kV). To ensure that the amorphized layer at the apex of the tip did not impact the measurement, the layer was first removed in the La-APT. The complete removal of the damaged layer was evident from the absence of Pt in the mass spectra and the presence of crystallographic poles on the 2-D detector hit map.

\section{Enhanced light absorption in semiconducting material damaged by an ion beam}

To evaluate the change in the optical properties of $\mathrm{Si}$ and GaN post ion beam irradiation, we first performed PMOR measurements on bulk samples with different implanted $\mathrm{Ga}^{+}$doses, i.e. different levels of damage (Section 3.1). We then studied how these modified properties affected atom probe measurements (Section 3.2).

\subsection{Impact of FIB damage and amorphization on the optical properties of bulk semiconductors}

To investigate the modified properties of Si and GaN following FIB irradiation, we used a $30 \mathrm{kV} \mathrm{Ga}^{+}$beam to implant $100 \times 100$ $\mu \mathrm{m}^{2}$ regions of bulk $\mathrm{Si}$ and $\mathrm{GaN}$ samples with different $\mathrm{Ga}^{+}$doses ranging from $10^{13}$ to $10^{16} \mathrm{~cm}^{-2}$. We then looked at how the PMOR signals vary as a function of the total dose (Fig. 2). The PMOR signal is a measure of the optical absorption efficiency of the sample. More specifically, PMOR is a pump-probe technique wherein a modulated-power pump laser heats up the sample and hence modifies its refractive index [18]. The pump-induced modulation of the refractive index is then measured by the modulated reflectance of the probe laser, i.e. the so-called PMOR signal. Such photoreflectance techniques are commonly used in the semiconductor industry to study the damage caused by ion implantation because the pump-induced heating and PMOR signal scale with sample damage $[19,20]$. In this paper, the PMOR measurements were obtained at room temperature using a thermaprobe TP630XP tool, where the NIR pump laser has a $790 \mathrm{~nm}$ wavelength (photon energy $\mathrm{E}_{\mathrm{ph}}=1.57 \mathrm{eV}$ ), a modulation frequency $v_{\bmod }=1 \mathrm{MHz}$ and a probe wavelength of $670 \mathrm{~nm}$. Most importantly, $E_{\mathrm{ph}}$ is larger than the bandgap of c-Si but lower than the bandgap of c-GaN.

Fig. 2(a) shows the PMOR signals measured on the bulk Si and GaN samples irradiated by a normally incident $30 \mathrm{kV} \mathrm{Ga}^{+}$beam as a function of the implanted dose to investigate what enhancement of the supra- and sub-bandgap light absorption was generated by the $\mathrm{Ga}^{+}$irradiation. Fig. 2(b) shows the same data on a linear scale including also non-irradiated $\mathrm{Si}$ and GaN samples. Focusing first on the behavior of the Si data in Fig. 2(a), two regimes can be 

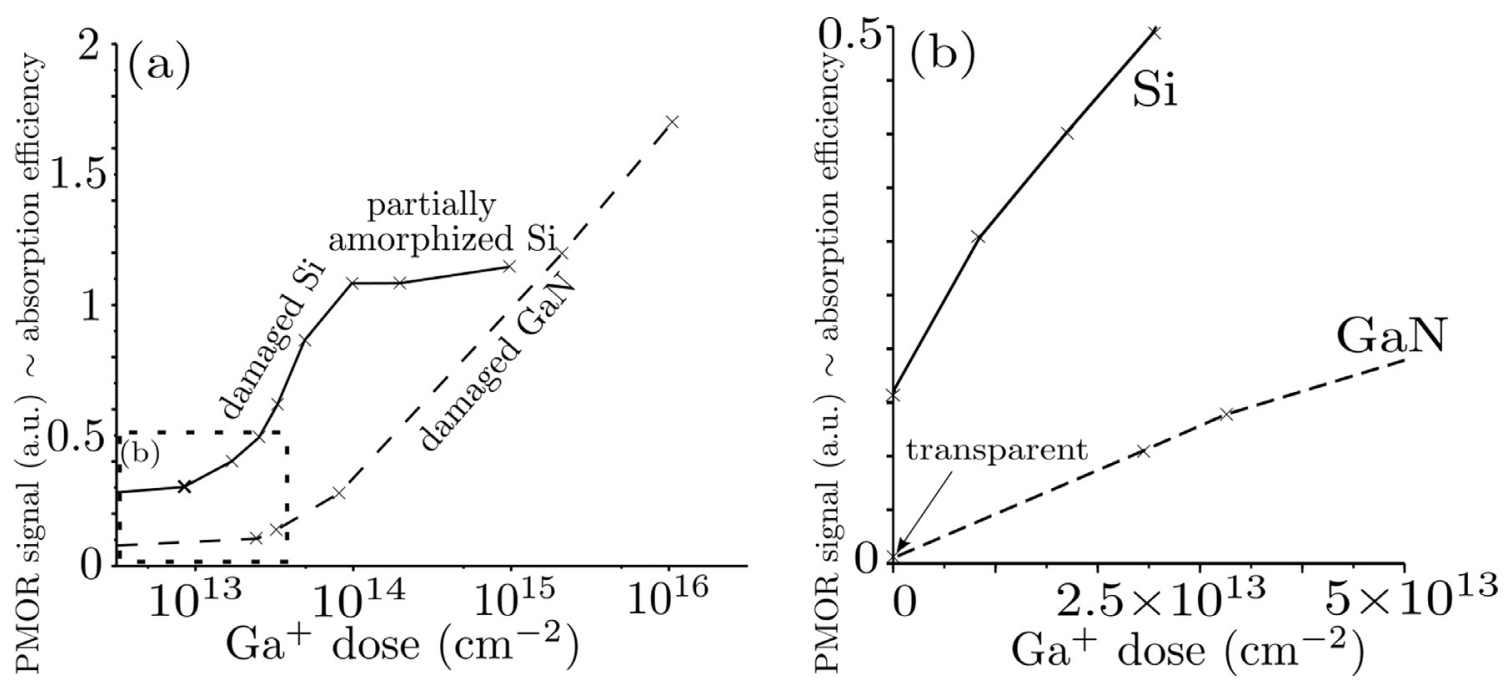

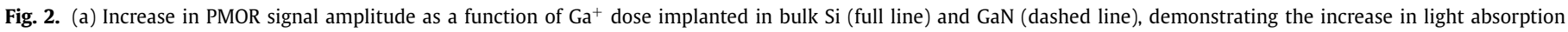

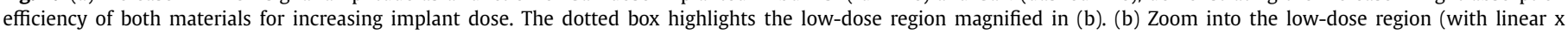
scale), where the PMOR signal measured on pristine GaN drops to zero, as expected given the transparency of pristine GaN to the NIR pump laser.

distinguished. For an implantation dose of less than $\sim 10^{14} \mathrm{~cm}^{-2}$, a monotonic increase in PMOR signal is observed, which demonstrates a damage-induced increase in light absorption efficiency. For a dose $>10^{14} \mathrm{~cm}^{-2}$, the PMOR signal starts to saturate. This saturation has been observed for Si damaged with $\mathrm{Au}, \mathrm{Kr}, \mathrm{Ar}, \mathrm{Si}, \mathrm{Ge}$ and Ga [24,25] using a similar dose, and is referred to as the dose required for partial amorphization. As observed in Fig. 2(a), once Si is partially amorphized, its absorption coefficient slowly increases with ion dose. The absorption is expected to plateau as soon as the full amorphization dose i.e. $5 \times 10^{15} \mathrm{~cm}^{-2}$ [25], is reached. Indeed, once fully amorphized, further damage cannot occur and a fixed absorption coefficient should result. Secondly, Fig. 2(a) shows that, despite the expected transparency of GaN to the NIR pump laser, GaN can also be turned into an absorptive material by damaging it with FIB. As highlighted in Fig. 2(b), the pristine GaN sample $\left(\mathrm{Ga}^{+}\right.$dose $\left.=0\right)$ expectedly shows a negligibly small PMOR signal, attributed to background noise. It was also verified that this signal does not change when increasing the pump laser power or the distance between the pump and probe beams on the sample surface (not shown). For higher $\mathrm{Ga}^{+}$doses, however, the nonzero PMOR signal clearly indicates significant absorption of the NIR pump light. Moreover, the PMOR data acquired from the GaN seems to indicate a larger amorphization dose in GaN than in $\mathrm{Si}$, in agreement with previous studies [26,27]. This difference is reported to be induced by a very efficient dynamic annealing of the GaN during ion implantation [27].

\subsection{Impact of FIB damage and amorphization on semiconducting atom probe tips}

The PMOR measurements of Fig. 2 indicate that the presence of the amorphized layer leads to enhanced absorption of light and can even turn a transparent material into an absorptive medium. To demonstrate the impact of these phenomena on the nanoscale conical geometry of an La-APT tip, we studied the variations in tip temperature as a function of different amorphized shell thicknesses illuminated using a green laser. Starting with $\mathrm{Si}$, three tips were milled at $30 \mathrm{kV}$. One tip was kept as milled while the two remaining tips were cleaned at an acceleration voltage of $5 \mathrm{kV}$ and $1 \mathrm{kV}$ respectively. As already shown and discussed in Fig. 1, this produced 3 tips of different amorphization layer thicknesses ranging from $\sim 5 \mathrm{~nm}$ ( $1 \mathrm{kV}$ cleaning) up to $25 \mathrm{~nm}$ ( $30 \mathrm{kV}$ milling). Caution was, however, taken to keep the geometries of the tips virtually identical [half cone angle $\theta \sim 3.5^{\circ}-4.5^{\circ}$, Fig. 3(b)]. The tips were then analyzed at $80 \mathrm{~K}$ and under green laser illumination $\left(\lambda=515 \mathrm{~nm}\right.$, i.e. $\left.\mathrm{E}_{\mathrm{ph}}=2.4 \mathrm{eV}\right)$ using the Laser-Assisted WideAngle Tomographic Atom Probe (LAWATAP) of Cameca. The variation in evaporation flux as a function of the charge state ratio $\left(\mathrm{CSR}=\mathrm{Si}^{2+} /\left(\mathrm{Si}^{2+}+\mathrm{Si}^{+}\right)\right)$for the emitted $\mathrm{Si}$ ions at a constant laser power $(\mathrm{P}=6.3 \mathrm{~mW})$ were studied. As shown in Fig. 3(a), the CSR, and hence the electric field [28], required to reach a certain evaporation flux decreases as the $\alpha$-Si shell thickness increases. Since the electric field and temperature at the apex are the only two driving forces for field-evaporation during La-APT [3], a higher flux for the same CSR implies the tip apex has reached a higher temperature. Hence, these measurements indicate that the temperature reached at the apex of a Si tip scales with the acceleration voltage used for its FIB preparation, in agreement with the FIB-induced enhancement of the light absorption demonstrated on films presented in Fig. 2.

To demonstrate that a similar FIB-induced absorption enhancement exists on a priori transparent materials, we repeated the experiment on GaN tips $\left(E_{g}=3.5 \mathrm{eV}\right.$ [17]) milled at $30 \mathrm{kV}$ and cleaned at $8 \mathrm{kV}, 5 \mathrm{kV}$ and $1 \mathrm{kV}$ respectively, again using a green laser $\left(E_{\mathrm{ph}}=2.2 \mathrm{eV}<\mathrm{E}_{\mathrm{g}}\right)$ with a power of $1.4 \mathrm{~mW}$. Again, care was taken to keep the geometries of the tips similar [half cone angle $\theta \sim 3^{\circ}-4.5^{\circ}$, Fig. 4(b)]. As shown in Fig. 4(a), akin to Fig. 3(a), the evaporation flux at a fixed Ga CSR, i.e. electric field, increases as the $\alpha-G a N$ shell thickness increases. Here the apex temperature can again be understood to scale with the final acceleration voltage used for the tip preparation. Note, however, that analysis of a GaN tip milled at $30 \mathrm{kV}$ acceleration voltage led to local circular deformations of the tip as observed in the micrograph of Fig. 4(c). This was never observed with the low-energy cleaned tips, even after analysis at a higher laser power. This would imply that even higher temperatures on a localized scale were reached along the tip shank. The results presented demonstrate the important role played by the $\alpha$-GaN shell in the successful measurement of a GaN tip despite the expected transparency of GaN to green light.

For the sake of completeness, we would like to add that the shape of the mass spectra can also be impacted by the amorphized surface shell. Most dramatically, the so-called thermal hump present in the mass spectrum of Si measured with infrared light $\left(\lambda_{0}=1030 \mathrm{~nm}\right.$ ) [29] can be shifted to higher or lower masses when the $\alpha$-Si shell thickness is changed, as illustrated in Fig. 5 


\section{Edited by Foxit PDF Editor \\ Copyright (c) by Foxit Corporation, 2003 - 2010 \\ For Evaluation Only.}

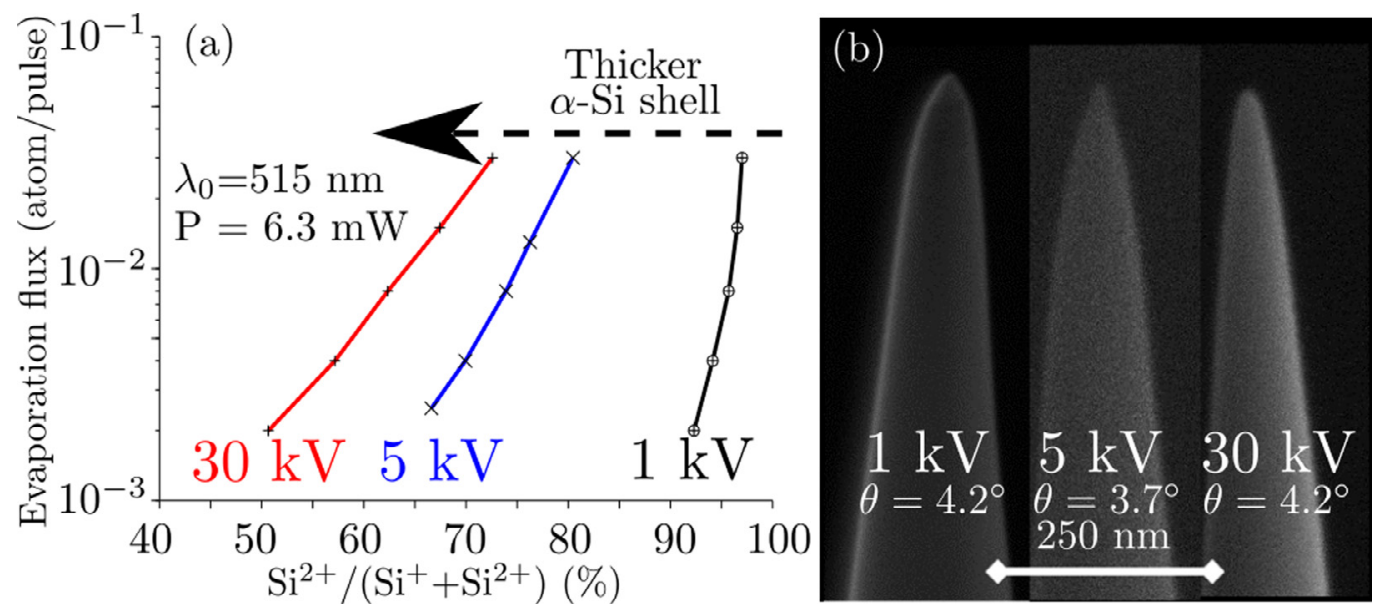

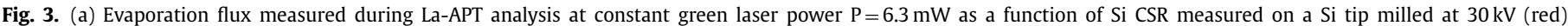

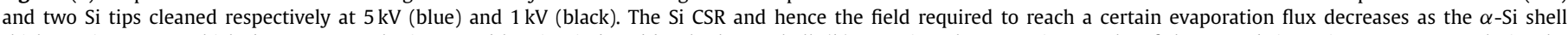

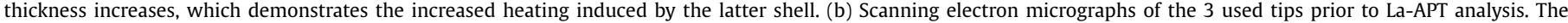
half cone angles $\theta$ are indicated for each tip. (For interpretation of the references to colour in this figure legend, the reader is referred to the web version of this article.)
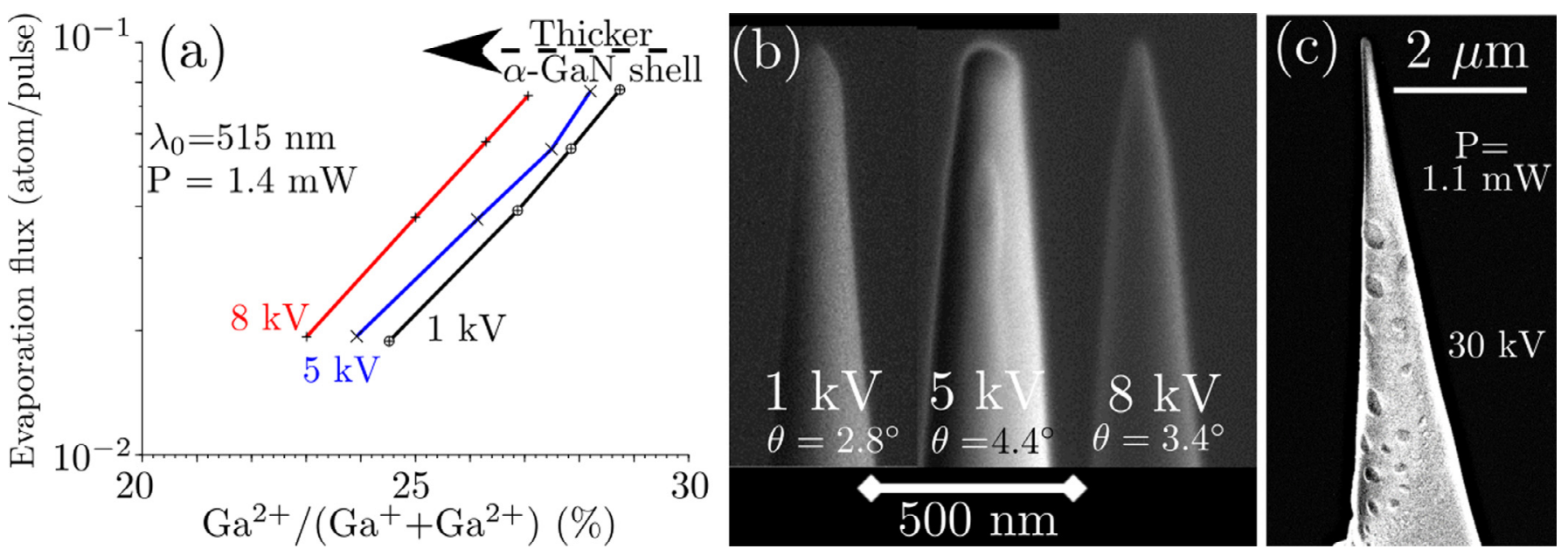

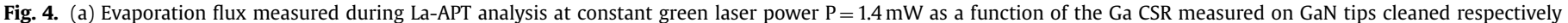

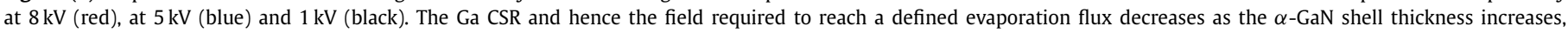

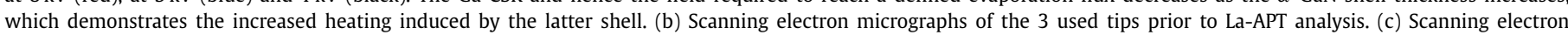

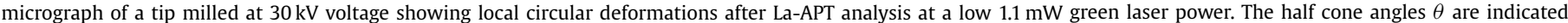
for each tip. (For interpretation of the references to colour in this figure legend, the reader is referred to the web version of this article.)

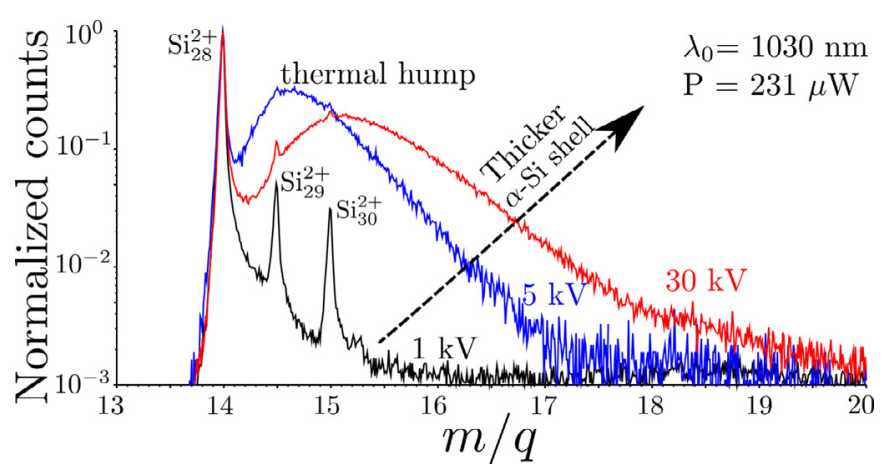

Fig 5. Normalized $\mathrm{Si}^{2+}$ mass spectra measured during La-APT analysis at constant infrared $\left(\lambda_{0}=1030 \mathrm{~nm}\right)$ laser power $\mathrm{P}=231 \mu \mathrm{W}$ on a Si tip milled at $30 \mathrm{kV}$ (red) and two Si tips cleaned respectively at $5 \mathrm{kV}$ (blue) and $1 \mathrm{kV}$ (black). The position of the thermal hump shifts with the acceleration voltage used during the tip preparation with FIB. The tip cleaned at the lowest $1 \mathrm{kV}$ acceleration voltage does not exhibit any thermal hump even at higher IR laser power. (For interpretation of the references to colour in this figure legend, the reader is referred to the web version of this article.) which shows the mass spectra acquired in IR for the three Si tips of Fig. 3(b). As can be observed, the position and width of the thermal hump are different for all three tips, and is attributed to a degradation of the thermal diffusivity of the tip due to the presence of the amorphized shell [30]. Furthermore, the mass spectrum acquired from the tip cleaned at the lowest $(1 \mathrm{kV})$ acceleration voltage does not exhibit any thermal hump, even at higher laser powers. This points to a much lower tip temperature and absorption in the $1 \mathrm{keV}$ cleaned tip, and again shows the critical impact the tip preparation conditions may have on the laser-tip interaction. Note that, using green and ultraviolet wavelengths, a similar but less striking improvement of the mass resolution was also obtained on the tip cleaned at $1 \mathrm{kV}$ acceleration voltage (not shown).

\section{Conclusion}

In this paper we have studied the impact of FIB preparation on the optical properties of Si and GaN. It was shown that the use of FIB to mill, clean or even only image the tip, results in an amorphized shell at the tip surface which has a higher absorptivity than 
the crystalline core of the tip. The presence of the amorphized shell enhances the absorption efficiency and hence the heating of a tip under either supra- or sub-bandgap illumination. This absorption enhancement increases with increasing amorphized shell thickness such that the tip apex temperature scales with the acceleration voltage used during the FIB tip preparation. The shape of the mass spectrum can also be dramatically affected by the FIB preparation. These observations have both experimental and theoretical consequences. From an experimental viewpoint, the reduction in the amorphized shell thickness can be used advantageously to improve the mass resolution. Conversely, the amorphized shell thickness can be tuned to target a certain temperature and hence facilitate the evaporation. From a theoretical standpoint, any model attempting to describe the laser-assisted evaporation process in LaAPT needs to include the effects of the FIB-induced amorphized layer. This is valid in the case of an absorptive crystalline core, as demonstrated using Si tips here while also when the crystalline core is transparent to the laser light, as shown with the example of GaN tips.

\section{Acknowledgments}

The authors would like to thank Dr. Y. Saripalli and the GaN team of imec for the GaN sample as well as the Structural Analysis team of IMEC for the transmission electron micrographs. Andrzej Gawlik is acknowledged for the PMOR measurements. We also thank Dr. R. Morris for his help.

\section{References}

[1] B. Gault, F. Vurpillot, A. Vella, M. Gilbert, A. Menand, D. Blavette, B. Deconihout, Rev. Sci. Instrum. 77 (2006) 043705.

[2] Y. Amouyal, G. Schmitz, MRS Bull. 41 (2016) 13-18.

[3] T.F. Kelly, A. Vella, J.H. Bunton, J. Houard, E.P. Silaeva, J. Bogdanowicz, W. Vandervorst, Curr. Opin. Solid State Mater. Sci. 18 (2014) 81-89.

[4] M. Gilbert, W. Vandervorst, S. Koelling, A.K. Kambham, Ultramicroscopy 111 (2011) 530-534
[5] D.J. Larson, T.J. Prosa, D.E. Perea, K. Inoue, D. Mangelinck, MRS Bull. 41 (2016) 30-34.

[6] L. Arnoldi, E.P. Silaeva, A. Gaillard, F. Vurpillot, I. Blum, L. Rigutti, B. Deconihout, A. Vella, J. Appl. Phys. 115 (2014) 203705.

[7] R. Agrawal, R.A. Bernal, D. Isheim, H.D. Espinosa, J. Phys. Chem. C 115 (2011) 17688-17694.

[8] E.A. Marquis, N.A. Yahya, D.J. Larson, M.K. Miller, R.I. Todd, Mater. Today 13 (2010) 34-36.

[9] A. Vella, B. Mazumder, G. Da Costa, B. Deconihout, J. Appl. Phys. 110 (2011) 044321.

[10] D. Santhanagopalan, D.K. Schreiber, D.E. Perea, R.L. Martens, Y. Janssen, P. Khalifah, Y.S. Meng, Ultramicroscopy 148 (2015) 57-66.

[11] E.P. Silaeva, M. Karahka, H.J. Kreuzer, Curr. Opin. Solid State Mater. Sci. 17 (2013) 211-216.

[12] E.P. Silaeva, L. Arnoldi, M.L. Karahka, B. Deconihout, A. Menand, H.J. Kreuzer, A. Vella, Nano Lett. 14 (2014) 6066-6072.

[13] B. Gault, M.P. Moody, J.M. Cairney, S.P. Ringer, Atom Probe Microscopy, Springer, New York Heidelberg, 2012.

[14] T. Dinh, H.-P. Phan, T. Kozeki, A. Qamar, T. Fujii, T. Namazu, N.-T. Nguyen, D. Viet Dao, Mat. Lett. 177 (2016) 80-84.

[15] H.-P. Phan, T. Kozeki, T. Dinh, T. Fujii, A. Qamar, Y. Zhu, T. Namazu, N.-T. Nguyen, D. Viet Dao, RSC Adv. 100 (2015) 82121-82126.

[16] S.M. Sze, Physics of Semiconductor Devices, 3rd Edition, Wiley, 2007.

[17] I. Vurgaftman, J.R. Meyer, L.R. Ram-Mohan, J. Appl. Phys. 89 (2001) 5815

[18] J. Bogdanowicz, Photomodulated Optical Reflectance, Springer-Verlag, Berlin Heidelberg, 2012.

[19] W. Vandervorst, T. Clarysse, B. Brijs, R. Loo, Y. Peytier, B.J. Pawlak, E. Budiarto, P. Borden, in: AIP Conference Proceedings, 683, 2003, p. 758.

[20] A. Salnick, J. Opsal, J. Appl. Phys. 91 (2002) 2874.

[21] M.K. Miller, K.F. Russell, K. Thompson, R. Alvis, D.J. Larson, Microsc. Microanal. 13 (2007) 428

[22] J. Mayer, L.A. Giannuzzi, T. Kamino, J. Michael, MRS Bull. 32 (2007) 400-407.

[23] J.F. Ziegler, J.P. Biersack, The stopping and range of ions in matter, in: D.A. Bromley (Ed.), Treatise On Heavy-Ion Science 6, Springer Science+Business Media, New York, 1985.

[24] C. Wilbertz, K.L. Bhatia, W. Kraetschmer, S. Kalbitzeret, Mat. Sci. Eng. B2 (1989) 325-331.

[25] G.P.S. Balasubramanian, R. Hull, J. Mater. Sci. Mater. Electron. 26 (2015) 4513.

[26] C. Liu, A. Wenzel, B. Rauschenbach, E. Alves, A.D. Sequeira, N. Franco, M.F. Da Silva, J.C. Soares, X.J. Fran, Nucl. Instrum. Methods Phys. 178 (2001) 200-203.

[27] S.O. Kucheyev, J.S. Williams, S.J. Pearton, Mat. Sci. Eng. R 33 (2001) 51-107.

[28] D.R. Kingham, Surf. Sci. 116 (1982) 273-301.

[29] A. Vella, Ultramicroscopy 132 (2013) 5-18.

[30] H. Wada, T. Kamijoh, Jpn. J. Appl. Phys. 35 (1998) 648-650. 